\title{
NEW METHODOLOGICAL THEORETIC APPROACHES TO THE ANALYSIS OF SPORT ACTIVITY
}

\author{
Dr. Marina Bogdanova, Associate Professor of the Philosophy Chair \\ Southern Federal University, Rostov-on-Don, Russia \\ E-mail: maraleks27@mail.ru
}

Received: March, 18.2015. Accepted: April, 14.2015.

Studies and articles

UDK 796.01

\begin{abstract}
Based on the views of representatives of domestic and Western philosophical thought (M. Merleau-Ponty, P. Bourdieu, N.A. Bernstein, E. Knyazeva), the author offers a nontraditional approach to the study of essence and nature of sports activity. The productive analysis of sports activity requires such technics of intellectual procedures, which allow to consider sports activity not only as a physical sphere but also as a mental one, including cognitive, mental, psychomotor and emotional aspects.
\end{abstract}

Keywords: Sports activities, Methodological theoretic approaches, Sportsman's body, Embodiment, bodily thinking, M. Merleau-Ponty, Habitus, P. Bourdieu, N. A. Bernstein, Living movement, Social facilitation.

At the turn of XIX and XX centuries in the philosophy of science the necessity of revision of the basic positions of classical philosophical tradition has become increasingly recognized and, above all, the concepts of the completely independent, "transcendental subject of thought, devoid of any bodily, spatial, and temporal characteristics are being revised. Convinced of the uselessness of opposing of "bodily" to "spiritual", the philosophers have started searching for the "matter", "shapes" of thought that precede and prepare the acts of consciousness. So, in modern Western philosophy, especially in phenomenology and existentialism the concept of "corporeality" appears, removing the opposition between natural and artificial, mind and body, subject and object. The body in these philosophical concepts is not reduced to the object, and the soul to the subject; the body is replaced by embodiment and is understood as a selfgoverning system, meaningful and effective.

In recent years, Russian humanitarian science has had a number of interesting studies,

Corresponding Author

Dr. Marina Bogdanova, Associate Professor of the Philosophy Chair, Southern Federal University, Rostov-onDon, Russia

E-mail: maraleks27@mail.ru which, overcoming the dichotomy between social and biological in human nature, allow raising a new problem of body and spirit in the various manifestations of human culture.

The result of this research was the conclusion that the human bodily experience is the basis in which all acts of human consciousness are initially formed and organized, including the linguistic forms of expression and awareness (individual or communicative modes) and, therefore, all knowledge and existence of knowledge. The parameters and mechanisms of cultural existence depend largely on bodily organization, not only in terms of its material representation, but also at the level of the highest manifestations of the spirit. As E. Knyazeva noted: "the embodiment of consciousness does not mean denying the ideality of its products, but indicates the necessity of taking into account physical determinants of spiritual activity and cognition" (Knyazeva, E. N., 2008).

But while in the theoretical sphere the main vectors of understanding of the problem of interrelation of body and spirit have been introduced, the previous stereotypes continue to be evident in the sphere of practical implementation. According to J.-L. Nancy, the West is experiencing bodily catastrophe. In Western culture the body increasingly alienates from the subject. Modern Western culture has lost the original experience of the body, this experience remains the privilege of the "Third world". The West has to deal not with the whole body, and with the "flesh", "skin", "faces", "muscles". In other words, modern Western culture is dealing with bodily fragments, but not with the whole of the human body: "the flesh" is the property of cultivated sexuality, "skin" - the object of various kinds of cosmetic manipulation, "muscle" - the concern of bodybuilding.

The analysis of sporting activities allows going from the abstract, discursive knowledge 
of the body to the living somatic experience through a special way of an organized body movements. Sports activities are the type of human activity, in which the natural corporeality of man and his deliberate effort is most visibly and tangibly met to transform the embodiment in accordance with the social patterns that can be found in the current forms of physical culture.

The long development of sports practices have demonstrated their outstanding role in the formation of the human body. Every kind of sport has its own parameters: spatialtemporal characteristics, methods of application of energy and so on, which optimally should provide the required result. During many years of training an athlete's body takes the specific form of a gymnast, weightlifter, football player, swimmer, which becomes easily recognizable. Engaging in professional sport, the athlete literally "sculpts" his bodily form, therefore, his body is a focus of natural and cultural achievements.

It is known that modern professional sport requires long and hard workouts from the athlete. Effective execution of a motor action assumes that the athlete must reach a very specific type of relationship with the surrounding space using his body, it also suggests the completely new boundaries of his bodily existence.

The phenomenon of "probe" is widely known and described in psychological science. The meaning of this phenomenon lies in the fact that while feeling or touching this or that object, a person uses a probe that can make his feelings exist outside his body, in the world of external things. The probe would become a part and a natural extension of the man's body.

For us the most interesting phenomenon here is that many sports, as we know, presuppose using various kinds of sports equipment (for example, a ball in football, gymnastic ribbons, boards in windsurfing, etc), which being acquired by an athlete, become a kind of "probe". The athlete, who managed to adapt his body to the shape and properties of the object, gets the opportunity to enhance the potential of his body, its aesthetic appearance. "Qualified performer becomes the owner of new, more powerful abilities of perception perception of their own movements and abilities... The whole experience, which he has due to his skill, differs in quality and size, unavailable for an unskilled performer and he understands and perceives aesthetically a lot of that quality experience" (Peter, 1997).
The well-mastered object ceases to exist as an external object, outside the athlete body, and it becomes his natural and necessary part. The German sports specialist H. Gumbrecht, exploring the causes of aesthetic appeal of sport, prioritizes the achievement of symbiosis between the man and sporting equipment.

The beauty of sports, according to $\mathrm{H}$. Gumbrecht, is based on the feeling that sports equipment in some incomprehensible way fuses with the human body, becoming its harmonious continuation, especially in such sports equipment as cars, boats, weapons, or animals, when the athlete enters in almost "personal relationship with them ".

H. Gumbrecht writes: "Any rider knows that the jockey who constantly uses the whip, will not achieve the same number of victories as a jockey, using his own movements to step the horse. In the last seconds of hard struggle the body of the rider, exactly bent over the horse's neck seems to be getting longer and longer, adjusting to the rhythm of the horse" (Gumbrecht, H. U., 2006).

The aesthetics of the athlete's body is manifested not only in a perfect shape (harmonious proportions of the skeleton plus the ideally beautiful body shape), but in the process of execution of motor actions. The aesthetic content of a sports movement is not always an end in itself, to a greater extent it lies in its appropriateness and usefulness for the final result: running is beautiful not because the athlete has a goal - to run beautifully. He runs beautifully because running is correct, he runs better than the others; the beauty of his movement is a sure indicator of its functional effectiveness. An expedient, economical, effective method or a style is usually the most beautiful. V. Kuts writes about the beauty of the combat and movements in Russian fist fights: “...beautiful performance is always faster and more accurate, and therefore always increases the probability of achieving the goal» (Kuts V., 2006). Therefore, beauty in the sport means high sports techniques and skills to achieve results that are superior to ordinary habitual norms, and therefore, fascinate anyone involved in a sports action. "Beauty is some excess, a joyful surprise" (Kuts V., 2006). However, as history of sports shows, success was achieved by those athletes whose physical parameters were far from perfect. The famous Brazilian footballer Garrincha, two-time world champion in the national team of his country, had one leg $6 \mathrm{~cm}$ shorter than the other one, but this did not prevent him from demonstrating the highest technique and 
a truly beautiful game.

According to the researchers of creativity, it finds itself where there is no place for a standard, mechanical mode, where there is people's desire for perfection and victory over themselves. In sports there are a lot of opportunities for man's creative abilities, for going beyond the usual boundaries. Improvisational accuracy, instant guessing of the only correct decision in this ever-changing game situation, when conscious choice of options is simply impossible, no doubt, brings together the features of seeing, thinking, and motor responses in athletes with similar mental processes in art.

The search and application of new, innovative, original techniques and solutions is available in all sports. For example, in football the large size of the playing field, the absence of time restrictions on the ball possession, the ability to perform technical skills with any part of the body, except hands, etc. provide athletes with opportunities for choice and application of a variety of technical-tactical actions.

An acute sense of time and space is a key point for all sports, which manifests itself in a situation of absolute merge feeling of space and momentum to the movement.

The density and the hostility of the outside world is determined for the athlete by the oppositions: predictability - unpredictability, transparency - non-transparency, development - non-development, which is specified and calculated in the course of an infinite number of workouts. As a result, the external world, which is becoming "his" world, begins to lose its density, as if dissolving into the subject. Designed and developed so the world of external things gradually begins to disappear, the athlete ceases to notice it, for example, to hear and to feel the elasticity and density of water, ice, gravity and density of his own body, etc.

The clear criterion for the development of space and its elements is in itself his "disappearance", now the athlete begins to interact with it without facing any difficulties, almost without noticing it. So, as well as the development of language, one learns to use it quite unconsciously, finding it difficult even to reflect grammatical rules. The language, which he has mastered turns out to be "swallowed", and there are difficulties that a man sometimes faces, the essence of the difficulty is not how to speak, but what to say.

Very special experience, familiar to every professional athlete is described in sports pedagogical literature. These are such complex feelings as "feeling of water" "for swimmers, "a sense of the boat progress for rowers, "the feeling of the ball - for footballers (basketballers, volleyballers and so on), "apparatus feeling" - for gymnasts. Only in case if an athlete has this kind of "feelings" and the possibility to rely on them in the process of solving motor tasks, sports victories and records are possible.

This means that hard exercising has led to a change in the "body scheme" in the sense that the external environment in its current subject state was perceived by the athlete "internally", as a continuation of his body.. Thus, the objective world ceases to be external space, which is forcedly overcome, specially submitted by the athlete; the athlete and the environment is now, in fact, are in a state of cooperation, they complement each other, creating the impression of a harmonic blend. The environment is not acting as something alien, hostile, it becomes such a reality that already "implies" the athlete and needs him. N. A. Bernstein, describing the living movement, wrote: "The most significant feature that distinguishes the living movement from the mechanistic one, is that it represents not only the movement of the body in space and time but also the mastery of space and time, i.e. it has the features of an active chronotope" (Bernstein, N. A., 1966).

Recognizing the physicality decisive role, M. Merleau-Ponty believes that there are bodily threads that control the mind and establish our design method and understanding of the world. M. Merleau-Ponty introduced the concept of "body scheme" or "body pattern " that define and limit the possibilities of consciousness. "Body schemes" are a special kind of a life style, which organizes the movement of my body and determines its interaction with the surrounding world. What is a burden of the sick person? Following M. Merleau-Ponty, the answer might be the following: not so much physical sufferings, but the necessity to get rid of the traditional way of life, to restrict activities and circles of interaction with other people.

Or, as M. Merleau-Ponty says, to change "a global pattern of your body", i.e. to change your life style for some time or forever. For example, a headache is not just a pain in the head, but the cancellation of the planned work, the inability to read a book, to watch a movie. The disease is not seen as a disruption of a biological body, but as the collapse of the living space, which is out of persaon's control and which immerses people into the new, and therefore alien world. 
When professional athletes finish their career, they are faced with the necessity to change the body boundaries. It is clear that the parameters of the life of athletes define serious bodily trials and loads, and are accompanied by vivid emotional experiences. In the new post-sport life situations it is very difficult for an athlete to reproduce his previously familiar life style. Hereafter his life-world is significantly different from the past, both in terms of physical and mental stress and vital and meaningful moments. A former athlete finds himself in the position in which he is devoid of usual reference points, familiar surroundings, and he faces a problem of revolutionizing his body pattern, and, in the end, the reconstruction of the entire world. This "work" on requiring a new "feeling body" is extremely difficult and problematic due to the fact that, for obvious reasons, the feeling of the athlete's body is a paramount value.

For the purposes of the study of the cognitive nature of the sports activity the concept of Bourdieu "habitus" is of great interest. In the philosophical tradition habitus is the mixture of the individual bodily skills - gait, gestures, manners, which are a reflection of a person's individual experience. The habitus is generated by social and natural environment through its interiorization by a man and it is the expression of his social life trajectories. Bourdieu associates habitus with a lifestyle, which in ensemble combines mental and physical preferences of the man when he chooses a certain scheme of personal practices, perception and evaluation of events, a set of lexical resources for communication.

The main feature of habitus is that it is an unconscious structure: these are the systems of deeply rooted preferences of individuals, which are neglected and therefore not reflexive: "Habitus is a story that has become nature, and thereby it denies being such" (Shmatko N. A., 1998).

Unconsciousness of habitus is defined by its physicality; installation and preferences (or "dispositions" by Bourdieu) are inscribed in the body and manifest themselves in an individual behavior, style and the habit to choose one or the other scenario of communication, to talk, to behave and to move.

According to the experts in the field of physical culture, the range of sports over recent decades has expanded to more than 240 disciplines through such informal sports like skydiving, freeclimbing, paragliding, rafting, windsurfing, etc. "The extreme complexity of the dynamic relationship between the body of the athlete, technical equipment (sails, boards, parachute) and natural elements (water, wind or impassable routes) represent a really serious challenge to the person corresponding to the values of the XXI century" (Dant T. and Wheaton B. Windsurfing, 2007).

What is common between all of these sports? It is the involvement of a person interacting with the complicated technical equipment in a masterly movement in space, for whom the perception of speed and control over all elements of this process is the essence of competitive activity. At the highest level all of these sports require very high "investments in physical capital". To become a participant in such a competition, the athlete must learn to achieve "virtual intuitive" control over the interaction of complex technical equipment, its physicality and natural environment: this should happen unconsciously, so that the equipment becomes "prosthetic continuation of the human body", and the wind force or the wave length - his additional reserves (Dant T. and Wheaton B. Windsurfing, 2007).

Ever-expanding range of new sports which stir the imagination with their complexity opens new possibilities of the human body and leads to the problematic nature of the concept of "biological norm". As K. Paciello noted: "And athletic, and "adventure" sports have become a kind of laboratory where the endless expansion of possibilities of the human body in every conceivable way is globally demonstrated" (Paciello K., 2006).

Greatest moments in sports are not the exclusive property of not only those who create them; but also of spectators who watch and enjoy physical superiority of the man. In this regard, the athlete is similar to the actor, he is also interested in "finding a contact" with the audience, to get their support, to feel their emotions.

Powerful competitive motive inherent in the very nature of sports activities makes the sportsman find hidden resources in his body, initiates the operation of the athlete to master the new techniques and methods, which is also manifested in the effect of "social facilitation". Social facilitation - a socio - psychological phenomenon of increasing the activity efficiency when it's done either in the presence of other people, or in a situation of competition. First social facilitation was observed and described in the late nineteenth century (V. M. Bechterev, L. Lange, F. H. Allport and others). One of the manifestations of social facilitation was the situation described by researchers on the cycling track. Cycling track was arranged 
in such a way that the audience members were located only on one side of the track. It turned out that regardless of the coach's tactical plans just before the stands with spectators athletes committed involuntary acceleration and tried to show their best results.

\section{CONCLUSIONS}

So, it's not possible to adequately describe sports activity just within the framework of traditional approaches to the description of physical culture. There is a need to introduce new methodological theoretic bases of the sports activity analysis, which will take into consideration the inseparability of the psychic and the physiological, the mental and the bodily, feeling and action. The works of M. Merleau-Ponty, P. Bourdieu, N. A. Bernstein, E. Knyazeva offer conceptual provisions of the theory of "bodily thinking", which can become a new research strategy of the sports activity study. They will make it possible to understand the anthropological nature of sport and make a transfer from abstract, discursive knowledge about man's body to living somatic experience, including all cognitive sphere.

\section{Conflict of interests}

Author declare no conflict of interest.

\section{REFERENCES}

Bernstein, N. A. (1966). Essays on the physiology of the movements and physiology of activity. Meditsina, Moscow.

Dant T., Wheaton B. Windsurfing (2007). An extreme form of material embodied interaction? AT Anthropology today. Special issue. December. Vol 23(6).

Gumbrecht, H. U. (2006). In praise of athletic beauty. Harvard University Press. Transl. from English. Pheschenko. New literary review, 2009.- 176 p.

Knyazeva, E. N. (2008). Autopoiesis of thought. Tomsk State Pedagogical University Bulletin, 1(75), 47.

Kuts V. (2006). Century Culture of Self-Defense. Russian Fist Fight. Rostov n/D: Phoenix; St. Petersburg: North West.

Paciello K. (2006). Sport as a universal social phenomenon. National notes. 3 (6). 54-66.

Peter J. Arnold. (1997). Aesthetic aspects of sports. Sports, spiritual values, culture: theoretical concepts and applied programs. Sports, aesthetics, art. Vol. 5: RSAPC, Humanit. center "SpArt"M, 85-98.

Shmatko N. A. (1998). Habitus in the structure of sociological theory). Journal of sociology and social anthropology, 1(2). 60-70. 
(IJCRSEE) International Journal of Cognitive Research in Science, Engineering and Education Vol. 3, No.1, 2015. 